\title{
A low-pressure portable anaesthesia system for field use: clinical trials
}

W.A. Tweed MD FRCPC,* Roshna Amatya MBBS DA, $\dagger$ W.E. Spoerel MD FRCPC*
This is a report of our experience with a portable anaesthesia system that was developed for use under field conditions, when compressed gas supplies are limited. We first assembled and bench-tested a low-pressure plenum system, based upon the Farman entrainer. The entrainer required a low flow of compressed gas, $\mathrm{O}_{2}$ at $\mathrm{l}-2 \mathrm{~L} \cdot \mathrm{min}^{-1}$, and generated a lowpressure mixture of $\mathrm{O}_{2}$ and air which was directed through an Oxford miniature vaporizer, a non-return valve, and a widebore T-piece circuit. With this system we anaesthetized 24 patients with intermittent positive pressure ventilation (IPPV) and nine patients breathing spontaneously. During IPPV, the circuit resembled a T-piece and provided effective gas exchange with a FGF of 1.2 times minute ventilation. Inspiratory and expiratory valves were arranged so that the spontaneous mode was non-rebreathing, and FGF was adjusted to equal minute ventilation. The system was very economical, using $1-2$ $\mathrm{L} \cdot \mathrm{min}^{-1} \mathrm{O}_{2}$ and $20-25 \mathrm{ml} \cdot \mathrm{hr}^{-1}$ liquid halothane to produce a FGF of $6-10 \mathrm{~L} \cdot \mathrm{min}^{-1}$, an $\mathrm{F}_{1} \mathrm{O}_{2}$ of 0.33 , and $\mathrm{Fl}_{\mathrm{hal}}$ of $1-1.5 \mathrm{per}$ cent. We have demonstrated that this is a versatile, safe, and economical system, compatible with the practice of modern inhalational anaesthesia under field conditions. It can be readily assembled from commercially available components.

On reporte notre expérience avec un système d'anesthésie ambulant qui a été développé pour l'urilisation dans les conditions de champ de bataille quand la réserve de gaz comprimé est limitée. On a initialément assemblé et testé au laboratoire un système de soufflerie à basse pression basée sur le "Farman entrainer ". Le souffleur a fonctionné à des flots bas de gaz comprimé $\mathrm{O}_{2}$ à $\mathrm{I}-2 \mathrm{~L} \cdot \mathrm{min}^{-1}$, el généré un mélange à basse pression d'oxygène et d'air el a été dirigé vers un vaporisateur miniature $O x f o r d$, une valve uni-directionnelle, et

\section{Key words}

ANAESTHETIC TECHNIQUES: inhalation; EQUIPMENT: anaesthesia machines.

From the Departments of Anaesthesia, University of Western Ontario, London, Canada, ${ }^{*}$ and Tribhuvan University, Institute of Medicine, Kathmandu, Nepal. $\dagger$

Address correspondence to: Dr. W.A. Tweed, Department of Anaesthesia, University Hospital, London, Canada, N6A 5A5. un circuit comprenant une pièce en $T$ de grand calibre. Avec ce système, on a anesthésié 24 patients avec une ventilation intermittente à pression positive (IPPV) et les neuf patients raspiraient spontanément. Ourant l'IPPV, le circuit ressemblait à la pièce en $T$ et fournissait un échange gazeux efficace avec un FGF de 1,2 fois de ventilation à la minute. Les valves respiratoires et expiratoires ont été arrangées afin d'éviter la réinspiration lors de la ventilation spontanée et le FGF fut ajusté pour égaler la ventilation à la minute. Le système fut très économique utilisant $1-2 \mathrm{~L} \cdot \mathrm{min}^{-1}, \mathrm{O}_{2}$ et $20-25 \mathrm{ml} \cdot$ heure $^{-1}$ $d$ ' halothane liquide afin de produire un FGF de 6-10 L $\cdot \mathrm{min}^{-1}$ et $\mathrm{FlO}_{2}$ de 0.33 et une Fi halothane de $1-1.5$ pour cent. On a démontré que ce système versatile, sécuritaire et économique est compasible avec la pratique de l'anesthésie d' inhalation moderne dans les conditions de champs de bataille. Ce système pourrait être assemblé sur le champs à partir d'éléments disponibles commercialement.

In an accompanying report we describe the components and gas flow characteristics of a low-pressure, plenum anaesthesia system incorporating the Farman entrainer' ${ }^{\prime}$ to deliver a fresh gas mixture of ambient air and oxygen. This system was designed for general anaesthesia in field conditions and under-serviced areas, especially where supplies of compressed gases are limited. It requires only a low flow of source gas to drive the Farman entrainer, i.e., $1-2 \mathrm{~L} \cdot \mathrm{min}^{-1} \mathrm{O}_{2}$ at a pressure of less than 200 $\mathrm{mmHg}$.

Because the bench studies had demonstrated that fresh gas flow rates (FGF) in the system were dependent upon the diameter of the delivery tubing and the resistance to flow of the breathing circuit, we chose a wide-bore, low-resistance $T$ piece for the clinical trial. The configuration of the assembled system is illustrated in Figure 1. It consisted of a compressed $\mathrm{O}_{2}$ source, a Farman entrainer, an EMO, an Oxford Miniature Vaporizer (OMV), an Oxford Inflating Bellows (OIB), and a T-piece circuit. For clinical use the T-piece circuit was configured in four ways, for different patient and ventilatory requirements. We have used it in all four modes but report results only for controlled intermittent positive-pressure ventilation (IPPV) and spontaneous breathing.

1 In the IPPV mode a mechanical ventilator was attached 
LOW PRESSURE PLENUM ANAESTHESIA SYSTEM

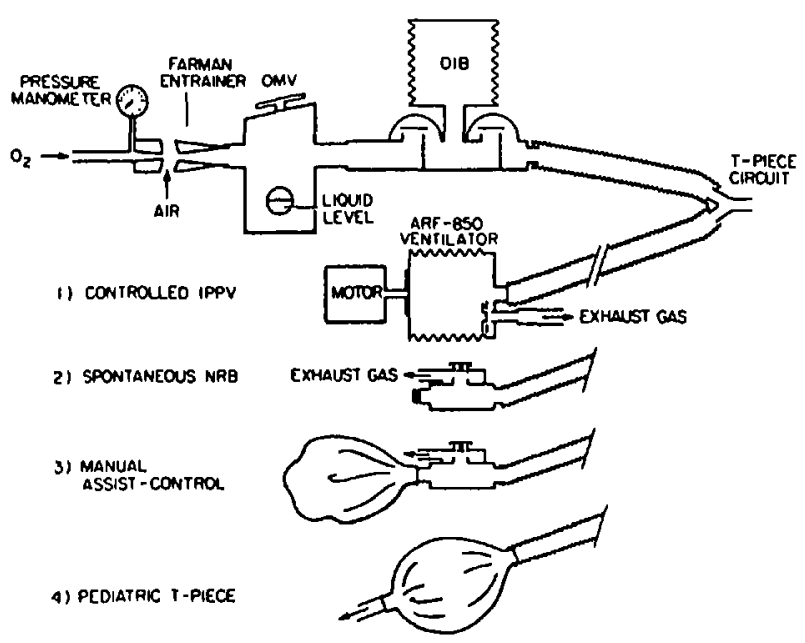

FIGURE I A schematic drawing of a portable low-pressure plenum system. OMV is the Oxford miniature vaporizer, OIB is the Oxford inflating bellows. The ARF-850 ventilator was used for IPPV.

to the efferent limb. We used an electrically driven ARF-850 ventilator, supplied by Acoma Medical Instrument Co.Ltd., Japan. In this mode the circuit resembles a T-piece.

2 In the manual control-assist mode the ventilator was replaced by a reservoir bag and expiratory relief valve.

3 For spontaneous breathing the reservoir bag was removed and the open end of the expiratory relief valve was plugged. Since there were one-way valves on both inspiratory and expiratory limbs this was a nonrebreathing (NRB) circuit, and the OIB served as the fresh gas reservoir.

4 With the expiratory limb left open, the circuit was used as a simple low-resistance $T$-piece for paediatric anaesthesia. It could also be used with a Jackson-Rees attachment to the reservoir limb.

Each of these circuits facilitates scavenging of waste gases, which was usually practiced.

The clinical trial was conducted in the operating theatres of Tribhuvan University Teaching Hospital, Kathmandu.

\section{Methods}

Thirty-three patients were studied using the system, 24 with IPPV and nine breathing spontaneously. The studies were conducted in accordance with Departmental and Institutional standards.

Subjects selected for study were ASA physical status I and II patients receiving general tracheal anaesthesia. Induction was with thiopentone $3-5 \mathrm{mg} \cdot \mathrm{kg}^{-1}$ and succinylcholine $1 \mathrm{mg} \cdot \mathrm{kg}^{-1}$. After tracheal intubation anaesthe- sia was maintained with halothane $/ \mathrm{O}_{2} /$ air and meperidine $0.4-0.6 \mathrm{mg} \cdot \mathrm{kg}^{-1}$. For IPPV, either gallamine or $\mathrm{d}$ tubocurarine was given for muscle relaxation. The inspired halothane concentration was maintained at 1.0 to 1.2 per cent with the aid of an Engstrom EMMA Multigas Monitor (Gambro Engstrom AB, Box 20109, S-161, 20 Bromma, Sweden). The source gas in all cases was compressed $\mathrm{O}_{2}$, delivered through a rotameter flowmeter from a Mera anaesthetic machine.

Measurements were made of FGF through the circuit, expiratory minute ventilation (VE), and inspired oxygen concentration $\left(\mathrm{FIO}_{2}\right)$. Each recorded measurement was the mean of 3-5 readings. Arterial blood was also sampled anaerobically and arterial blood gases (ABG) were analyzed with a Corning 165 Blood Gas Analyzer. Serum bicarbonate and base excess were estimated from a Siggaard-Anderson nomogram. A complete set of measurements was made after surgery had begun and stable anaesthesia conditions were established.

Gas flows were measured with a Medishield RM 121 (Wright) respirometer which had been calibrated with an ACOMA PH-3F rotameter type flowmeter, and oxygen concentration with an ACOMA model AS-25 oxygen analyzer calibrated with room air (ACOMA Medical Instrument Co. Ltd., Japan). The blood gas analyzer was calibrated with a standard gas before each analysis.

Oxygen and halothane use were estimated volumetrically. The halothane vaporizer was refilled with a $20-\mathrm{ml}$ syringe at the end of each case to determine halothane consumption. Auscultatory blood pressure (BP) and heart rate (HR) were recorded every five minutes.

Kathmandu is at an altitude of 1300 metres with an average barometric pressure of $650 \mathrm{mmHg}$. These data are not corrected for temperature or pressure.

\section{Results}

Data for 33 patients is presented in the Table. Arterial blood gases were obtained from 28 patients, 22 with IPPV and six with spontaneous respiration.

Demographic data are shown first. Most patients in this study, as in the general Nepali population, were small by North American standards, muscular, and lean. The surgical procedures of the IPPV group were mainly abdominal and gynaecological, but chiefly orthopaedic and ENT for those breathing spontaneously. Halothane consumption was higher with spontaneous respiration, in part because they required a higher concentration to maintain clinical anaesthesia, and also because FGF was higher.

Data for pulmonary ventilation and FGF rates are normalized for body weight. Tidal volume was smaller, rate higher, and total minute ventilation greater in spontaneously breathing patients. FGF was 1.18 times VE 


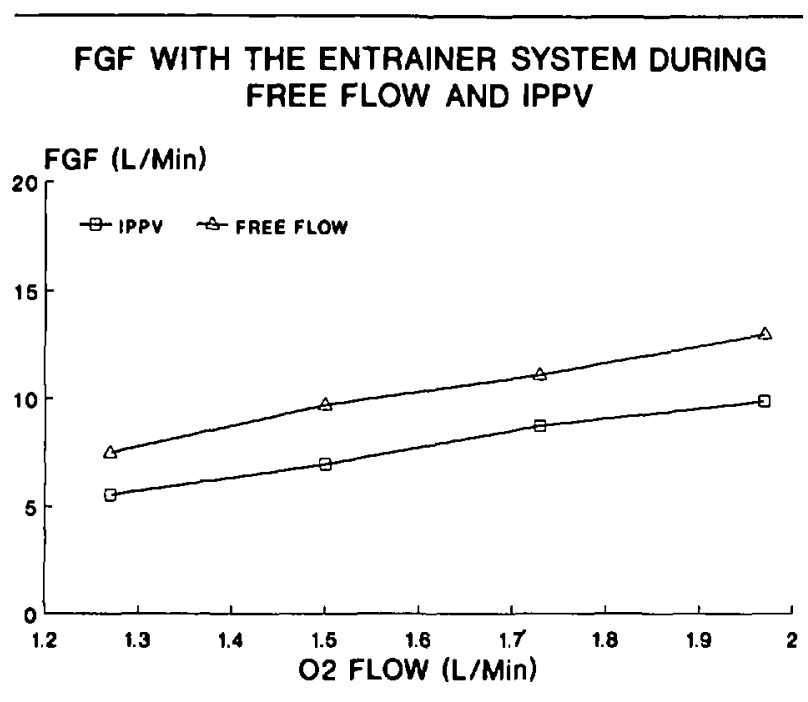

FIGURE 2 Fresh gas flow at various $\mathrm{O}_{2}$ flow rates during IPPV (rate of $12 \mathrm{bpm}$ and $\mathrm{I}: \mathrm{E}$ ratio of $\mathrm{I}: 2$ ), compared with that measured during free-flow conditions, that is with the patient connector open to atmosphere. The air $/ \mathrm{O}_{2}$ entrainment ratio during free flow was about $6: 1$ and during IPPV about $4: 1$.

during IPPV; 1.02 times VE during spontaneous breathing.

The $\mathrm{ABG}$ results are shown next. $\mathrm{PCO}_{2}$ was higher in spontaneously breathing patients, but both groups were within the clinically acceptable range for general anaesthesia. The same applies to BP and HR, with a decrease in systolic BP and no change in HR characteristic of halothane anaesthesia.

Figure 2 compares FGF measured during bench testing, with the patient connector open and the circuit free flowing, with actual FGF during IPPV (I:E ratio of $1: 2$ and rate of $12 \mathrm{bpm})$. During free flow the air $/ \mathrm{O}_{2}$ entrainment ratio was about $6: 1$, but it was reduced to about $4: 1$ during IPPV anaesthesia.

\section{Discussion}

Most modern anaesthesia machines are unsuitable for use under field conditions and in under-serviced areas of the world. The major limiting factor is that compressed gases are often unavailable or very scarce. ${ }^{2}$ For the same reasons rebreathing systems, dependent on $\mathrm{CO}_{2}$ absorbers, are impractical. The practical solution is to use ambient air as the main carrier gas for inhalational anaesthesia. This is the principle of the EMO and OMV which were designed by the Oxford group in the 1950s and $60 \mathrm{~s}$, the Triservice apparatus, and similar systems which are still widely used. ${ }^{3,4}$ However, such equipment was not designed for the practice of modern anaesthesia.

We began these studies with the premise that modern anaesthesia could be practised in under-serviced and remote areas of the world by adapting existing equipment. A continuous flow or plenum system was required, but
TABLE Patient data

\begin{tabular}{|c|c|c|c|c|c|}
\hline \multirow[b]{2}{*}{ Variable } & \multicolumn{2}{|c|}{ Controlled } & \multicolumn{2}{|c|}{ Spontaneous } & \multirow[b]{2}{*}{$P$} \\
\hline & Mean & $S D$ & Mean & $S D$ & \\
\hline Age yr & 36.8 & 12.8 & 31.7 & 11.2 & NS \\
\hline Weight kg & 46.4 & 7.4 & 54.1 & 17.2 & NS \\
\hline Anaes. lime hr & 1.35 & 0.48 & 1.93 & 0.93 & $<0.05$ \\
\hline Halothane used $\mathrm{ml} \cdot \mathrm{hr}^{-1}$ & 20.8 & 5.0 & 25.7 & 4.8 & $<0.05$ \\
\hline Tidal vol $\mathrm{ml} \cdot \mathrm{kg}^{-1}$ & 9.7 & 0.8 & 4.1 & 0.8 & $<0.000$ \\
\hline Resp rate & 12 & & 37 & 5 & \\
\hline $\begin{array}{l}\text { Minute vent. } \mathrm{ml} \cdot \mathrm{kg}^{-1} \text {. } \\
\min ^{-1}\end{array}$ & 116 & 10 & 150 & 24 & $<0.000$ \\
\hline FGF $\mathrm{ml} \cdot \mathrm{kg}^{-1} \cdot \min ^{-1}$ & 137 & 18 & 154 & 55 & NS \\
\hline $\mathrm{FGF} / \mathrm{min}$ vent & 1.18 & 0.1 & 1.02 & 0.32 & $<0.05$ \\
\hline Driving press. $\mathrm{mmHg}$ & 51 & 6 & 57 & 6 & 0.001 \\
\hline $\mathrm{FiO}_{2}$ & 0.33 & 0.02 & 0.33 & 0.01 & NS \\
\hline $\mathrm{PCO}_{2}$ & 44 & 5 & 49 & 6 & NS \\
\hline $\mathrm{PO}_{2}$ & 127 & 27 & 127 & 40 & NS \\
\hline $\mathrm{pH}$ & 7.35 & 0.07 & 7.36 & 0.04 & NS \\
\hline Bicarb meq $\cdot L^{-1}$ & 26.2 & 4.1 & 28.2 & 1.5 & NS \\
\hline BE meq $\cdot L^{-1}$ & 1.4 & 4.4 & 3.2 & 1.2 & NS \\
\hline Syst BP mmHg pre-ind. & 115 & 16 & 111 & 16 & NS \\
\hline Lowest & $96^{*}$ & 11 & 93* & 10 & NS \\
\hline Heart rate bpm pre-ind. & 83 & 14 & 79 & 6 & NS \\
\hline Lowest & 86 & 17 & 85 & 16 & NS \\
\hline
\end{tabular}

Data for 24 patients during general anaesthesia with IPPV and 9 breathing spontaneously. Statistical comparison was by the unpaired t-test.

*Indicates $P<0.01$ compared with pre-induction.

one that did not make a heavy demand on compressed gases. An $\mathrm{O}_{2}$-driven Venturi with a high air $/ \mathrm{O}_{2}$ entrainment ratio, the Farman entrainer, was selected and its flow characteristics were examined in a preliminary study. Based on those results we designed a simple system with a low-resistance T-piece breathing circuit and tested it in a clinical trial.

This study was not conducted with precise measuring instruments. We used clinical instruments, calibrated against the best available standards, and attempted to reduce random error by averaging several readings for each data point. It is likely, however, that overall measurement error was in the range of 5- 10 per cent. This also applies to $A B G$ analyses, since the analyzer was used infrequently, replacement electrodes were unavailable, and standard gases were of dubious purity. The high estimated values for bicarbonate and base excess, where there was no expectation of a metabolic alkalosis, suggests that there was a systematic overestimation of $\mathrm{PCO}_{2}$. We intend, therefore, to repeat these studies under better controlled conditions. Despite that reservation this trial is of unique value, since there is no substitute for evaluating new equipment under the actual conditions of intended use.

We chose the Oxford miniature vaporizer (OMV) because of its reliable performance under field condi- 
tions. ${ }^{5}$ It is a very low-resistance vaporizer and works equally well with plenum or draw-over flow ${ }^{6}$ and over a wide range of flow rates, ${ }^{7,8}$ Although a fluid reservoir provides temperature buffering it is not thermalcompensated, and output varies with both temperature and time. In this study the output seldom varied more than ten per cent from the dial setting.

The source gas for the entrainer was $\mathrm{O}_{2}$, delivered through a Mera rotameter flowmeter. However, any low-pressure compressed gas source would do: a portable $\mathrm{O}_{2}$ cylinder with a flow control valve or an oxygen concentrator. ${ }^{9}$ If $\mathrm{O}_{2}$ were not available compressed air could be substituted, or the entrainer could be removed converting the system to a draw-over mode. In normal clinical use we found this to be a very economical system, consuming 20-25 ml liquid halothane per hour and 1-2 $\mathrm{L} \cdot \min ^{-1}$ of $\mathrm{O}_{2}$.

The Oxford inflating bellows (OIB), with both valves functioning, is an integral part of the system. During the inspiratory phase of IPPV the distal valve of the OIB prevents back flow through the vaporizer. The bellows was left unlatched, acting as a secondary reservoir and allowing continuous forward flow from the entrainer through the vaporizer. The open bellows serves another important safety function as a visible monitor of continuous FGF. The distal valve of the OIB remains closed throughout inspiration, and opens early in expiration so that all FGF occurs during the expiratory phase. Functionally, therefore, this circuit resembles the T-piece circuit, and our studies suggest that adequate gas exchange can be achieved if FGF is 1.2 times minute ventilation. Some rebreathing undoubtedly occurred under the conditions of this study, and further investigations with capnography are required.

The circuit for spontaneous respiration was nonrebreathing, with separate inspiratory and expiratory non-return valves. This was confirmed many times; reverse flow was never observed in either limb. Waste gas was readily scavenged from the expiratory relief valve. In this mode the OIB bellows was the primary reservoir, and FGF equalled minute ventilation.

Although we believe the system as described is suitable for field anaesthesia, there are some necessary precautions in its use. Because it is a low-pressure system FGF is sensitive to changes in circuit resistance (Figure 2). This is particularly important during IPPV since a decrease in FGF would increase rebreathing. Although using the OIB as a secondary reservoir provides a visual check on FGF, an accurate flow meter is advisible until one becomes experienced with the system. When $\mathrm{O}_{2}$ is used as the source gas, $\mathrm{FIO}_{2}$ will not fall below 0.3 , and an $\mathrm{O}_{2}$ analyzer is unnecessary. However, a relatively fixed $\mathrm{FIO}_{2}$ is a limitation, and further developments will address the problem of $\mathrm{O}_{2}$ enrichment.

In summary we have described a simple anaesthesia system that allows the practice of modern anaesthesia under field conditions. In a clinical trial with both controlled and spontaneous ventilation, safe and efficient use of the apparatus was demonstrated. The total system can be readily assembled from commercially available components, and EMO draw-over systems can be easily converted. Improvements in anaesthesia technology, as we have proposed, in concert with increased training opportunities, ${ }^{10}$ can greatly improve the quality of anaesthesia available in remote and under-serviced areas.

\section{Acknowledgements}

We wish to thank the surgeons and anaesthetists of Tribhuvan University Teaching Hospital for their encouragement and assistance while performing these studies on their patients. In addition we express our particular appreciation to Dr. B.B. Swar, Chief of Anaesthesia of the Birendra Military Hospital, Kathmandu, for his advice and technical assistance.

\section{References}

1 Farman JV. Economical anaesthesia overseas: air entrainment device for use with draw-over vaporizers in children. Br Med J 1965; 1428.

2 Ezi-Ashi TI, Papworth DP, Nunn JF. Inhalational anaesthesia in developing countries. Part 1 . The problem and a proposed solution. Anaesthesia 1983; 38: 729-5.

3 Farman JV. Anaesthesia and the EMO system. London: English University Press, 1973

4 Merrifield AJ, Hill DW, Smith $K$. Performance of the Portablease and Fluoxair portable anaesthetic equipment. Br J Anaesth 1967; 39: 50-70.

5 Jowitt MD, Knight RJ. Anaesthesia during the Falklands Campaign. Anaesthesia 1983; 38: 776-83.

6 Parkhouse J. Clinical performance of the OMV vaporizer Anaesthesia 1966; 21 : 498-503.

7 Jensen $J K$. Halothankonzentrationen erreicht durch den "Oxford Miniature Vaporizer". Der Anaesthetist 1967; 16: 54.

8 Wilson IH, Page RJE, Yeats $M J H$. The Oxford miniature vaporizer in paediatric anaesthesia. An experimental study, Anaesthesia 1988; 43: 700-2.

9 Carter JA, Baskell PJF, Simpson PJ. The "Permox" oxygen concentrator. Anaesthesia 1985; 40: 560-5.

10 Maltby JR, Rana NB, Amatya R, Shrestha BM. Anaesthesia training in Nepal. Can J Anaesth 1987; 34: 5 I-5. 